Revue bibliographique pour le domaine irano-aryen

Volume 37-38-39 | 2018

Comptes rendus des publications de 2014-2016

\title{
Javier Álvarez-Mon, "The Introduction of Cotton into The Near East: A View from Elam"
}

\section{Rémy Boucharlat}

\section{(2) OpenEdition}

1 Journals

\section{Édition électronique}

URL : http://journals.openedition.org/abstractairanica/45351

DOI : 10.4000/abstractairanica.45351

ISBN : 1961-960X

ISSN : 1961-960X

Éditeur :

CNRS (UMR 7528 Mondes iraniens et indiens), Éditions de l'IFRI

Référence électronique

Rémy Boucharlat, " Javier Álvarez-Mon, "The Introduction of Cotton into The Near East: A View from Elam" », Abstracta Iranica [En ligne], Volume 37-38-39 | 2018, document 11, mis en ligne le 30 décembre 2018, consulté le 26 septembre 2020. URL : http://journals.openedition.org/ abstractairanica/45351 ; DOI : https://doi.org/10.4000/abstractairanica.45351

Ce document a été généré automatiquement le 26 septembre 2020.

Tous droits réservés 


\title{
Javier Álvarez-Mon, “The Introduction of Cotton into The Near East: A View from Elam"
}

\author{
Rémy Boucharlat
}

\section{RÉFÉRENCE}

Javier Álvarez-Mon, "The Introduction of Cotton into The Near East: A View from Elam", IJSOIA (International Journal of the Society of Iranian Archaeologists), vol. 1/ $\mathrm{n}^{\circ} 2$, 2015, p. 41-52.

1 La tombe d'Arjan, datée de la période Néo-Elamite IIIA 647-585 av. J.-C., à la frontière du Khuzestan et du Fars a livré une douzaine de pieces de coton, dont certaines étaient brodées de rosettes sur la bordure, sur d'autres avaient été cousues des bractées en or. Le coton, originaire de la vallée de l'Indus, est extrêmement rare au Proche Orient en Iran jusqu'au au 1er millénaire et seulement sous forme de fragments. Puis il est attesté à la cour assyrienne, encore très probablement importé. En revanche, à l'époque achéménide, la culture de la plante est reconnue en Egypte et à Bahrain, venue d'Inde. C'est de cette île proche de l'Elam qu'aurait été importé le coton qu'attestent les vêtements d'Arjan soit sous forme de fibre soit de tissu. 


\section{AUTEURS}

RÉMY BOUCHARLAT

UMR 5133 CNRS-Université de Lyon 